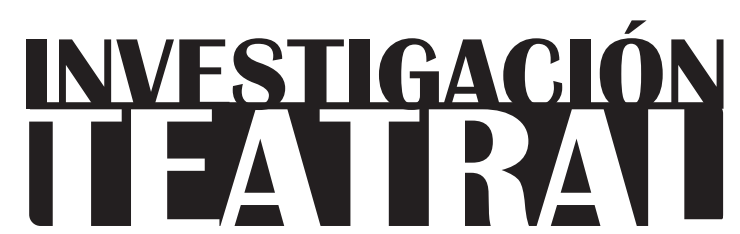

Revista de artes escénicas y performatividad

Vol. 12, Núm. 19

abril-septiembre 2021

Segunda época

ISSN impreso: $1665-8728$

ISSN electrónico: 2594-0953

Universidad Veracruzana

\title{
Teatro japonés y religión: dos facetas del rito
}

\author{
Violetta Brázhnikova Tsybizova*
}

Fernando Cid Lucas**
* Universidad Carlos iII de Madrid, España. e-mail: b.sumire@gmail.com
** Universidad de Valladolid, España.
e-mail:fernandocidlucas@gmail.com

Recibido: 05 de agosto de 2020

Aceptado: 19 de enero de 2021

Doi: $10.25009 /$ it.v12i19.2667 


\title{
Teatro japonés y religión: dos facetas del rito
}

\section{Resumen}

La danza ritual de la diosa Uzume se considera como la fuente legendaria del teatro nacional japonés. La descripción de cómo fue creado este género forma parte de la narrativa del Kojiki, la primera compilación japonesa de estas características, que data del siglo vin de nuestra era. En este artículo se presta especial atención a la relación entre el teatro tradicional japonés y el Shintō, la religión autóctona, para hacer así una aproximación al origen mitológico de ambos fenómenos. También se indaga en la compenetración estética y filosófica entre el teatro japonés y las religiones llegadas desde el continente a las islas japonesas en tiempos posteriores.

Palabras clave: shintō; zen; Nō; Zeami; Kojiki; estética; Japón.

\section{Japanese Theatre and Religion: Two Aspects of the Ritual}

\begin{abstract}
Goddess Uzume's ritual dance is considered the legendary source of Japanese national theatre. The description of how this genre was created is part of the narrative contained in Kojiki, the first Japanese compilation of its kind, from the $8^{\text {th }}$ century A.D. Special attention is paid in this article to the relationship between traditional Japanese theatre and the native Shintō religion, addressing the mythological origin of both. Attention is also paid to the aesthetic and philosophical rapport between Japanese theatre and the religions that travelled from the mainland to the Japanese archipelago.
\end{abstract}

Keywords: shintō; zen; Noh; Zeami; Kojiki; aesthetics; Japan. 


\section{Teatro japonés y religión: dos facetas del rito}

\section{Shintō: la deificación del emperador y las fuentes del teatro nacional} y la religión autóctona, el shintō (神道 “camino de los dioses”), es innegable. Esta religión ha tenido un impacto sin par en la consolidación de la Casa Imperial nipona, por cuya orden se procedió a sistematizar los mitos que la apoyaban. Desde la perspectiva histórica, podríamos citar el shintō folclórico y el de la Casa Imperial, vigente también en nuestros días. A continuación vamos a abordar la religiosidad, los orígenes del shintō y sus valores religiosos.

La historia de Japón se divide en varios periodos históricos, siendo las etapas iniciales especialmente importantes para el nacimiento de los ritos que nos interesan en el contexto de este artículo: la religión y el teatro. La primitiva cultura Jōmon (aprox. 14,500 a.C. - 300 a.C.) se desarrolló en las islas niponas una vez finalizada la última glaciación. Dicha cultura dejó como legado estético y presuntamente religioso numerosas vasijas de cerámica adornadas de una manera específica, característica de este período histórico; además de los utensilios más antiguos de toda la historia, según Junko Habu. También se fabricaron las figurillas dogū, cuyo uso en los ritos religiosos, no obstante, está todavía por demostrarse.

La cultura de Yayoi (300 a.C. - 250 d.C.) importó desde el continente el cultivo del arroz y los utensilios de hierro y de bronce. Durante este período se aprecian los primeros indicios de lo que más tarde sería la religión nativa de Japón, el shintō. Desde la antigüedad, los habitantes del archipiélago experimentan tal identificación con la naturaleza, que ésta inevitablemente penetra en todas las facetas de su vida diaria y religiosa. Esta compenetración 
resultó primero en creencias populares como el animismo, que no observaba uniformidad alguna, y posteriormente en una vía espiritual única sistematizada por los poetas del siglo viı. El investigador Federico Lanzaco Salafranca propone la siguiente división de los términos, prácticas y rituales del shintō:

a) Ceremonias grupales con ocasión de determinadas fechas del calendario tradicional japonés, y de especiales eventos en la vida de los japoneses. b) Asistencia periódica a los festivales locales (omatsuri) que se celebran en los santuarios sintoístas [...]. Estos festivales suelen expresar determinados ritos litúrgicos de comunión de la comunidad local con sus dioses tutelares para conseguir su protección [...]. c) peregrinaciones a santuarios famosos, normalmente edificados en medio de bosques [...]. En el recinto de estos santuarios se elevan peticiones para la familia e individuo [...]. d) Construcción del altar familiar en la propia vivienda (kamidana), con ofrendas renovadas de arroz, sake, flores (Religión y espiritualidad, 26-27).

Algunas de estas actividades religiosas están reflejadas en las obras del teatro Nō, especialmente en las piezas sobre las peregrinaciones que realizan los personajes a los lugares famosos a las que nos referiremos en este trabajo. En el primer acto de tales obras, los personajes suelen encontrarse con los kami del panteón shintoísta, que en el segundo acto revelan su verdadera identidad. Takasago sería uno de los ejemplos de esta práctica que hunde sus raíces en el shintō.

Desde el punto de vista mitológico, se considera que Japón se fundó como entidad política en torno al año 660 a.C. No obstante, el Estado-nación Japón aparece por primera vez en documentos mucho más tardíos: a partir del siglo iv de nuestra era. Más tarde se inicia el proceso de la deificación oficial de los emperadores debido al establecimiento de la Casa Imperial en la cúspide de la pirámide social. Las fechas aproximadas de este hecho corresponden al siglo vir a.C. Ya el primer monarca mitológico, Jimmu, manifiesta ser el nieto de los dioses. A partir de su coronación legendaria, los emperadores japoneses son consagrados como los kami vivientes, "divinidades del panteón shintoísta" (神).

Sin embargo, para justificar esta circunstancia, la mitología existente es revisada por un decreto imperial en tiempos posteriores. Por medio de la organización de la saga mitológica del momento, realizada por los poetas de la corte, se "demuestra" que los orígenes de la Casa Imperial nipona definitivamente hunden sus raíces en el mito de Amaterasu, la diosa del Sol y patrona del clan Sumeragi. Éste se encargó de unir bajo su poder a los demás clanes del Japón arcaico durante los siglos vi y vir. Se impulsó la creación del linaje imperial, que se ha mantenido operativo hasta la actualidad, vinculando los orígenes de la 
Casa imperial con la religión nativa de Japón. Por otra parte, el shintō se dividió paulatinamente en varias ramas: entre otras, el shintō folclórico y el shintō de la Casa imperial, ${ }^{1}$ que adoptó sus principales valores religiosos. Éstos acabaron extrapolados a toda la nación que se estaba consolidando.

Entre los numerosos episodios de la mitología ordenada en la compilación conocida como Kojiki, ${ }^{2}$ el siguiente tiene una importancia abrumadora para el pueblo del momento: la pareja y hermanos divinos Izanagi e Izanami son presentados como progenitores del "país de las cuatro mil islas", de su pueblo y de su estirpe imperial (Goreglyad 2-5). Como resultado de este proceso de legitimación del poder imperial surge una serie de signos, ritos, objetos y costumbres para su empleo exclusivo por la Casa imperial. Varios de ellos se siguen empleando en ocasiones puntuales; por ejemplo, los "Tres tesoros nacionales" (el espejo, la espada y la joya), cuya simbología no ha perdido su vigencia en el mundo actual. La mitología nipona describe la entrega de estos tres objetos que hace Amaterasu a Ninigi cuando éste se dispone a descender desde el Cielo hasta el monte Takachiho (en Kyūshū). Los mitos relatan que, al abandonar el poder, Ninigi cede los "Tres tesoros" a su nieto, Jimmu. Cada uno de los objetos sagrados cuenta con un pasaje propio en el Kojiki que explica su naturaleza y su procedencia. Éstas están ligadas al tan difundido mito de la Gruta Celeste que introduce el culto solar nipón: Amaterasu, hija de la pareja primigenia formada por Izanagi e Izanami, tras recibir graves afrentas personales de su hermano Susanoo, el dios de las tormentas y de las mareas, se enoja con él. Como consecuencia, decide retirarse en una gruta recóndita, sumiendo al mundo en la completa oscuridad. La diosa Ame-no-Uzume-no-Mikoto será la encargada de devolver la luz a la tierra. Esta diosa vigorosa del panteón shintoísta figura en cuatro capítulos del Kojiki. Además de considerarse la fundadora de la danza sagrada Kagura, cuyo origen está intrínsecamente emparentado con la escena que describimos a continuación, es recordada por su sensualidad y atrevimiento.

En el suceso de la Gruta Celeste (relatado en el capítulo 12) se organiza una estratagema en la que participan todas las divinidades afectadas por la decisión de la diosa del Sol. Entre los dioses reunidos ante la Gruta Celeste se elige a la diosa de la danza, que ofrece una puesta en escena espontánea con un único recurso escenográfico en forma de barreño de barro volteado. Uzume aprovecha varios elementos ajenos al arte de la danza para provocar la risa de las deidades. Al llegar al éxtasis sagrado en el proceso de la danza cómica se desprende de la ropa, mostrando sus partes más íntimas a los reunidos. Esta visión despierta la reacción

1 En la época Meiji (1868-1912), éste derivó en el denominado shintō estatal, cuyo predominio duró hasta el final de la Segunda Guerra Mundial.

2 古事記 (“Crónica de antiguos hechos de Japón”). Se trata de la primera crónica japonesa que se conserva, cuya compilación se llevó a cabo en el 711 o en el 712 de nuestra era. 
necesaria en el público (las carcajadas de las divinidades) cristalizando en una purificación masiva, de acuerdo con las creencias tradicionales japonesas. El sonido hueco que surge al golpear los pies contra este escenario sencillo y las risas, cuya auténtica razón la diosa del Sol desconoce, despiertan la curiosidad de Amaterasu, lo que provoca que ésta se asome. Lo primero que llama su atención es un espejo situado a la salida de la cueva. ${ }^{3}$ Atraída por su reflejo, Amaterasu pronto descubre el segundo tesoro, la joya, que está colgada de un árbol de sakaki. El último tesoro que descubre la diosa del Sol es la espada, hallada por Susanoo en una de las ocho colas de un maligno dragón de ocho cabezas en el país de Izumo. Al comprender la trampa de los dioses, Amaterasu trata de regresar a la gruta, pero se frena cuando esta última se cierra, con lo que el sol finalmente reaparece, devolviendo la vida a los seres vivientes. Así, una danza grotesca de Ame-no-Uzume (la intérprete), considerada posteriormente como la fundadora del género teatral del sarume $\lceil$ 猿女, los gritos y las risas de las demás divinidades (el público) y el uso de los “Tres tesoros sagrados” (la utilería), logran devolver la luz a la tierra, sucediendo así algo que podríamos comparar con la catarsis del teatro clásico griego.

La diosa del Sol, a su vez, da origen al legendario linaje imperial nipón (Goreglyad 9-10). De este modo, podemos comprobar que el mismo ciclo mitológico apoya teóricamente el nacimiento de dos tradiciones de indudable importancia para la consolidación político-cultural de Japón: la Casa imperial y el arte escénico, ambos originados de las creencias mitológicas, organizadas éstas en forma de dos manifestaciones estético-filosóficas: la compilación literaria del Kojiki y la religión shintō. Subrayemos que el estatus sagrado de los emperadores no se pierde en los tiempos posteriores, a pesar de los vaivenes históricos que en ocasiones reducen el poder de la Casa imperial, cediendo la autoridad al gobierno militar (bakufu) (ver Smith). ${ }^{4}$

\section{Los ritos del shintō como origen de las manifestaciones culturales}

En general, se considera que el propósito inicial de las tradiciones de origen shintoísta consiste en invitar a los fieles a participar de los fenómenos del mundo que les rodea. De allí que todavía exista un sinnúmero de expresiones de corte shintoísta en la vida diaria japonesa. Por ejemplo, en las orillas del lago Usori, en el Monte Osore, los visitantes depositan unas barquitas votivas llenas de comida y flores para los espíritus de sus seres queridos. Este

3 El espejo es uno de los elementos de culto que suele emplearse en los santuarios del shintō. Su principal propósito consiste en obligar al creyente a conocerse a sí mismo desde el punto de vista moral.

4 Existen ejemplos del poder político de los shogunes desde el periodo Heian, aunque el momento de su mayor relevancia se vincula al periodo Tokugawa (1603-1868). 
lugar, en la prefectura de Aomori, simboliza el miedo y la muerte; además es honrado como morada de las almas de los perecidos y como entrada al infierno. Las itako, "chamanas ciegas”イタコ」, que tradicionalmente asisten a esta y otras ceremonias relacionadas con el mundo de los muertos, se consideran mediadoras entre los vivos y los kami. Para lograr una comunicación fluida con los espíritus son largamente entrenadas desde edad muy temprana. De acuerdo con los estudios de Hugh de Ferranti, su ceguera es equiparada con la de los artistas itinerantes (biwa hoshi) de las épocas anteriores. En este contexto, la ceguera física no se consideraba un defecto o anomalía, más bien se trataba de un don ligado con la clarividencia (algo que en Occidente sucede, por ejemplo, con la figura de Homero).

Además de las itako, también es conocida la tradición de vestir al emperador con una nueva túnica para consagrar la primera cosecha de arroz en el altar sagrado. Este rito se remonta a uno de los mitos shintoístas concernientes al ciclo de Amaterasu. Asimismo, los ritos en torno a la fertilidad continúan teniendo una importancia de carácter estatal en el Japón contemporáneo. Además, se podría nombrar la costumbre de iniciar el año nuevo en primavera, vestir de blanco como símbolo de luto o recibir un regalo con las dos manos en señal de profundo respeto hacia el dador. Igualmente, otras prácticas shintoístas como las adivinaciones, la interpretación de los sueños o las supersticiones dan origen a un buen número de argumentos de los teatros Nō y Kabuki, aunque su práctica diaria se haya reducido notablemente.

En cuanto a la relación con la naturaleza, ésta tiene una presencia importante en la mentalidad japonesa de ayer y de hoy, hundiendo sus raíces en las creencias autóctonas. La historia del jardín japonés se remonta a la antigüedad y refleja la propia historia de las religiones niponas. Una porción de tierra consagrada (saniwa), delimitada y cubierta con pequeñas rocas lisas, constituía el lugar donde el emperador (o la emperatriz) se sentaba y tocaba un instrumento musical de cuerda para convocar a los reverenciados kami. Éstos pronunciaban un oráculo interpretado por el primer ministro. Este terreno sagrado se trasformaría luego en escenario, espacio originalmente destinado al establecimiento del contacto entre el mundo de los humanos y la morada de los dioses. Es de señalar que la actividad del teatro Nō sirve a esta función también en la actualidad, aunque la atmósfera que reina en las instalaciones donde se organiza el encuentro entre el actor (el mediador entre los dioses y los humanos) y el público (los fieles) difiere radicalmente de la que se buscaba en sus inicios. Un ambiente cercano al original se conserva solamente durante la puesta en escena de algunas obras excepcionales, cuya historia es anterior al surgimiento del teatro Nō. Okina es una de estas piezas que alimentan la antigua unión entre el espectador y los dioses.

Además de la influencia de las creencias locales, igualmente creemos importante mencionar el arte de construir y de cuidar los karesansui, “jardines áridos”「枯山水」. Este lugar simbólico ofrece al espectador la vista de unas piedras blancas (mar/océano) y unas rocas (islas) en el medio de un espacio vacío. La organización del espacio destinado a la medi- 
tación mantiene una relación especial con la rama Zen del budismo japonés durante el período Muromachi (1333-1573). Otras numerosas artes niponas están influenciadas por esta concepción material y filosófica que forjó el espíritu del bushi medieval. El arte del tiro con arco, la caligrafía, la pintura, el origami, la poesía y el teatro Nō son algunas de las vías $(d \overline{)})$ hacia el perfeccionamiento espiritual, con el satori, “iluminación”「悟り」, como último fin perseguido por los adeptos del Zen.

Generalmente, el influjo de los ritos religiosos se ha registrado también en otras expresiones filosófico-artísticas. Tal es el caso de Ikenobō, la escuela más antigua de ikebana, fundada en el templo Rokkakudō en Kioto. En el proceso de selección y colocación de las flores se funden los espíritus del shintō y del budismo clásico. Inicialmente, mediante esta manera se profesaba el culto a la diosa budista de la misericordia, Roppi Nyorin Kanzeon Bosatsu. Las ofrendas se realizaban en forma de flores, organizadas en el espacio de acuerdo con los principios de la triada cielo-tierra-hombre. Con el paso del tiempo, el ikebana pasó a ser uno de los signos inequívocos de la cultura japonesa. Su concepción original está llamada a crear la armonía y el equilibrio natural entre todos los elementos de la naturaleza, incluidas las plantas, ramas, piedras, troncos o el propio ser humano.

Definitivamente, el grado de influencia del shintoísmo en Japón es alto, incluso tras la llegada del Zen en el siglo xir. Por otra parte, sin duda alguna, muchos de los ritos antiguos no han sobrevivido hasta la actualidad. Por ejemplo, el uso ritual de la palabra hablada, cuyo valor en el shintō es primordial, está perdiendo paulatinamente su poder mágico ancestral, sobre todo entre la población más joven. No obstante, antiguamente el poder de la palabra era considerado tan grande que el simple hecho de que una muchacha revelara su nombre a un hombre prácticamente la convertía en su esposa. Esto se ilustra en el capítulo 32 del mencionado Kojiki, donde se describe esta costumbre y se explica cómo Kamuatatsu-hime se convierte en esposa de Ninigi-no-Mikoto (ver Goreglyad, 161-162).

\section{La influencia de las religiones en la concepción del teatro Nō}

A continuación proponemos inspeccionar el efecto que causaron otras religiones en el establecimiento del teatro Nō. Diremos que en los inicios del período Heian (794-1185) en Japón se desarrolló el espectáculo popular de los sarugaku hōshi o "monjes-mimos itinerantes”散楽法師」. El público era atraído por sus simples puestas en escena, que incluían varios números de acrobacias, malabares, zancos y danzas, que inicialmente no tenían un hilo conductor. Tampoco poseían carga simbólico-religiosa alguna. Estos grupos de actores, además de otros subgrupos del conjunto de intérpretes hōshi que operaban en este período histórico (biwa hōshi, dengaku hōshi, etc.), actuaban independientemente de las 
instituciones. Hacia el siglo xi, debido a los avances dramatúrgicos, los artistas del sarugaku hōshi unen varios números aislados en una farsa con un argumento simple, acompañada de un monólogo o un diálogo cómico en donde las situaciones de enredo o los equívocos tienen una gran relevancia. La creciente popularidad de los grupos de sarugaku hōshi hizo que los templos y los monasterios les ofreciesen su patrocinio, incluyendo sus espectáculos en las celebraciones religiosas.

En torno al siglo xir, estos grupos introducen en su repertorio algunas obras antiguas de clara concepción religiosa, por ejemplo, Okina, en la que se percibe la profunda huella del ritual shintoísta. Esta y otras obras arcaicas se incluirán posteriormente en el repertorio canónico del teatro Nō. Durante el siglo xil los actores errantes se instalan en los templos de forma indefinida, convirtiéndolos en sus sedes y uniéndose en $z a$, "gremio"「座」. Se cree que hacia 1246 las obras del ya denominado Sarugaku llegan a incluir tanto el canto como el baile con acompañamiento musical. La coexistencia en el mismo espacio de las actividades de culto y de las puestas en escena populares influyó en la consolidación de estas últimas. Una vida sedentaria en el territorio de los templos permitió a los actores perfilar su arte, hacerlo más refinado y emplear un léxico más cuidado y espiritual. Además, los intérpretes obtuvieron la oportunidad de aprender a leer y escribir. También accedieron a los textos budistas y a las obras literarias, lo que condicionó el contenido de sus representaciones y la concepción de las obras, cuyos textos por primera vez se fijarían por escrito (utaibon). Con el paso del tiempo, las escenas satíricas de carácter doméstico se sustituyeron por piezas que poseían un corte más filosófico, religioso o moral. Asimismo, comienza la tradición de describir en forma de tratados teóricos los avances y las normas de la técnica de actuación, transmitiendo sus secretos dentro de la misma línea de sucesión familiar, siempre al varón primogénito (ver: Yamazaki).

Las nuevas obras dramáticas recibieron el nombre de Nō, lo que significa: "técnica, arte, destreza...”「能」. Mientras tanto, las renovadas puestas en escena del Sarugaku pasaron a denominarse Sarugaku-Nō. Durante la era Muromachi, la influencia del Zen definió el mensaje filosófico de la mayor parte de las obras del teatro Nō. El reconocimiento oficial de este género sucedió en 1375, cuando recibió el apoyo público del shogun Ashikaga Yoshimitsu (1358-1408). Gracias al patrocinio de la poderosa casa Ashikaga, los actores del teatro Nō gozaron de gran popularidad y estima en la corte, tuvieron acceso a una educación esmerada y pudieron viajar por Japón para divulgar su arte. Ya bajo el gobierno de los Tokugawa, el Nō logró un verdadero florecimiento. A partir de 1603 las puestas en escena de este género teatral obtuvieron la forma inequívoca de un ritual religioso a causa de su contenido, tempo e influencia sobre el estado anímico y espiritual de sus participantes.

El desarrollo de los principios artísticos del Nō se asocia con los conceptos básicos procedentes de la doctrina Zen. Por ejemplo, la noción Zen de fusionar al sujeto con el objeto viene a significar, en el teatro Nō, la fusión de las emociones de los actores con 
las de los espectadores (ver Hekmat Fereshteh y Ghaffari). Como consecuencia, nacen dos principios de este género teatral: monomane, "imitación”「物真似」y yūgen, "belleza oculta"「幽玄」. Pero no se pueden obviar las influencias de otras vías espirituales, como la percepción budista de la naturaleza ef ímera de la vida y su carácter transitorio, que están vigentes en el momento de la consolidación del Nō y obtienen su lugar en la visión de sus autores (Gadjieva 15).

Hemos de recalcar que el actor de teatro Nō evita imitar la vida tal y como transcurre ante nuestros ojos. Por el contrario, procura revelar los cimientos ocultos de la realidad; el intérprete, en colaboración con la imaginación del espectador, procura dar una imagen completa y honda del mundo. Al público se le otorga una participación tan activa en el rito teatral como la que desarrolla el actor durante la representación. Se busca recibir una respuesta emocional del espectador, sumergido en una percepción completa. Esto explica la importancia que se le adjudica a la simbología de los gestos, los movimientos de los actores, el uso de la luz y la sombra sobre las máscaras, los decorados estilizados y reducidos a su mínima expresión, así como el carácter austero de la puesta en escena. Todos estos elementos ancestrales han venido a dificultar la comprensión del espectáculo por parte del espectador contemporáneo no iniciado en la poética del Nō.

Durante sus primeros años de formación, el teatro Nō recibió una influencia filosófica enorme por parte de los artistas pertenecientes a diferentes ramas. Los que tuvieron una mayor proyección fueron los creadores teatrales Kan'ami Kiyotsugu (1333-1384), su hijo Zeami Motokiyo (1363-1443) y sus seguidores. Sin embargo, también los poetas y los monjes Zen continuaron construyendo este complejo sistema de pensamiento teatral hasta su concepción total, ya en el Japón de los Tokugawa.

Tal es el caso de Ikkyū Sōjun (1394-1481), monje de la vertiente Zen y poeta, quien participó en el perfeccionamiento de la estética del teatro Nō. Además de su colaboración en el desarrollo de la ceremonia del té (Cha no yu) y de la estética de los jardines secos, Ikkyū concibió la unión de la palabra, la música, la danza y la interpretación en el espacio escénico del teatro Nō. Gracias a tales intervenciones el espectáculo obtuvo la forma que hoy conocemos: apareció el coro que cantaba en lugar del actor, sustituyendo una voz por varias. Distintos personajes pronunciaban el mismo texto, subrayando la identificación interior que existía entre ellos. Se creó el patrón definitivo del movimiento del actor en el escenario: la alternancia de las posiciones fijas y las transiciones rápidas de una postura a otra. La naturaleza de los movimientos de los intérpretes creó dos tipos de comportamiento del personaje en la puesta en escena del teatro Nō: el movimiento significaba la vida, mientras que la inmovilidad representaba la muerte. Los colores de los trajes, el color y la longitud de las pelucas, las máscaras y los decorados esquemáticos y alegóricos, así como los gestos y los movimientos de los personajes contenían un hondo significado 
simbólico. Se trataba de un lenguaje especial, altamente codificado, lo que supuso una sacralización de lo cotidiano.

El actor, por su parte, debía participar activamente en esta sacralización suprimiendo su "yo" interior mediante la máscara y el vestuario. Su mayor fin consistía en eliminar todo lo personal y lo individual de su ser, además de evitar que sus emociones internas tuvieran manifestaciones externas o pudieran modificar la psicología del personaje que encarnaba. La concepción teatral del Nō ha llegado hasta nuestros días, habiendo sufrido algunos cambios inevitables relacionados con el desarrollo histórico de la nación japonesa.

\section{Nociones de estética teatral de procedencia religiosa en el ámbito del Nō}

El ciclo mitológico de la diosa Amaterasu ha dado lugar a varios ritos de la religión autóctona japonesa. Éstos, por su concepción espacio-filosófica, a primera vista se alejan de las refinadas puestas en escena del polifacético Zeami. Sin embargo, entre el rito teatral y el rito religioso existen varios puntos en común. Por ejemplo, mientras que en el teatro Nō se sigue utilizando una imagen bidimensional de un pino pintado en el fondo del escenario, el Gran Santuario Kasuga de la antigua capital de Nara introduce un pino sagrado tridimensional en sus celebraciones religiosas (Anarina 119). Del mismo modo, los antiguos misterios que reproducen la danza de la diosa Uzume se desarrollan debajo de un pino situado en el territorio de este santuario shintoísta. Al igual que en las primeras puestas en escena del teatro Nō, el espacio se ilumina con antorchas durante el transcurso del misterio, que se representa de noche y que es conocido como Takigi Nō. La ceremonia se celebra para apaciguar el corazón de la diosa y termina con la llegada de los primeros rayos del sol, que salen -según la creencia- en respuesta a la danza mágica ofrendada. Los asistentes entienden entonces que el espectáculo ha sido del agrado de la divinidad solar, Amaterasu.

Tradicionalmente, se cree que el pino del kagamiita ("fondo del escenario en el teatro Nō”鏡板」) representa el árbol sagrado del Gran Santuario Kasuga. Es curioso descubrir que la traducción literal de kagamiita hace referencia al espejo. ${ }^{5}$ Igual ocurre con el nombre de la habitación donde los actores se transforman en el personaje. El término kagami-no $m a$, "habitación del espejo"「鏡の間」, también llama la atención por referirse al culto del sol, ya que el espejo se considera el símbolo mágico asociado a este astro. En otras palabras, son varios los elementos del teatro Nō que aluden patentemente al ciclo mitológico de la

5 El primero de sus ideogramas, "kagami” 「鏡」, quiere decir precisamente eso, "espejo". 
diosa Amaterasu, al que dicha forma teatral está intrínsecamente unida desde sus inicios más primitivos. Por otra parte, los conceptos estéticos mencionados antes brevemente, monomane y yügen, son de origen zenista y son solamente una pequeña parte de la paleta estética del teatro Nō. Uno de los mayores especialistas españoles en literatura japonesa, Fernando Rodríguez-Izquierdo, explica el concepto de yūgen del siguiente modo:

Cuando la visión del poeta es percepción súbita de algo misterioso y extraño, que apunta a lo arcano y desconocido, está allí presente el yūgen. Yūgen es un sentimiento de misterio, de larga tradición, pues ya se usaba en poesía china y escritos del Zen para significar lo arcano religioso. Con frecuencia en Laotzé o Chauntzé tiene un sentido enteramente filosófico, de esencia misteriosa de las cosas (218-220).

Así, en general, el ideal estético del teatro Nō busca el equilibrio entre la belleza y la utilidad, y se basa, a su vez, en los siguientes conceptos: wabi y sabi. Wabi se entiende como el encanto de lo cotidiano, mientras que sabi se percibe como una conexión entre la naturaleza y el arte, una materialización hecha por el hombre de aquello que nos regala, de manera tan generosa, la naturaleza. Lanzaco Salafranca considera que: "Esta palabra procede del verbo wabu (languidecer), y del adjetivo wabishi (solitario, sin recursos materiales)" (Los valores estéticos 92). De hecho, "los poetas medievales modificaron su sentido dándole un valor positivo, convirtiendo la soledad y pobreza en una liberación espiritual. Descubriendo una más profunda belleza en la falta de recursos" (ibidem), lo que se observa en la poesía de los tiempos posteriores, por ejemplo, en la obra del siglo XVII de Matsuo Bashō. Al margen de la poesía, este concepto tradicionalmente entendido como la belleza de lo imperfecto, es propio de otras expresiones artísticas y culturales japonesas. Tal es el caso de: "wabicha, como representación de todo el encanto y belleza de la ceremonia del té, enraizado profundamente en el camino del Zen" (ibidem). Con respecto a la pintura sumie, Lanzaco Salafranca afirma que es "una realización perfecta del valor estético 'wabi', de fuerte riagambre Zen" (ibidem). Según este autor, wabi "sugiere simplicidad 'esencial', una belleza natural que no es enmascarada con elementos decorativos accidentales superfluos. Este valor 'wabi' es uno de los distintivos principales de la estética japonesa" (Introducción a la cultura japonesa 345).

Por otro lado, según Fernando Rodríguez-Izquierdo:

Wabi se produce cuando el artista está deprimido o triste y capta algo ordinario, sin pretensiones, tal como es. Es el reconocimiento inesperado de la taleidad de las cosas ordinarias, y de su constancia frente a nuestra incertidumbre del futuro. Es un freno de la ambición humana, el bello halo de la pobreza (218-220). 
En cuanto a la noción de sabi, de acuerdo con la propuesta de Lanzaco Salafranca, la aparición de este término se vincula a la figura del poeta del siglo xiI Fujiwara Shunzei y sus estudios de crítica literaria. Sin embargo, "más tarde, en los siglos XIV y xV los conocidos escritores Zeami, Zenchiku y Shinkei utilizaron este término para expresar la belleza que se esconde en un paisaje frío y desolado. En el sustrato de este valor estético subyace una visión cósmica budista que resalta la soledad de la existencia humana, y anima a aceptar y alegrarse incluso de la misma" (Los valores estéticos 93-94).

Por otra parte, Rodríguez-Izquierdo en su ya célebre trabajo dedicado al haiku japonés, afirma que éste:

[...] está en la mente del observador; la expresión proviene de sabiru (oxidar). Es el sentimiento producido por un ambiente de soledad y quietud. [...] Es la soledad en el sentido del desprendimiento budista, que lleva a ver las cosas en su espontaneidad, sucediendo por sí mismas. Unido a este sentimiento está el de la quietud que se experimenta por ejemplo en una larga tarde o en una nevada. Sabi no es el tema del verso, sino su sabor y su color (218-220).

Los conceptos de wabi y sabi se relacionan estrechamente con los preceptos del Zen, y de ahí que actualmente no se puedan separar ni del haiku ni tampoco del teatro Nō. Ambas manifestaciones artísticas llevan implícitos los signos de naturalidad y, a la vez, de falta de un objetivo. Lo cierto es que, en general, la estética del Zen acentúa la sencillez y el silencio, tan propios de una puesta en escena de teatro Nō. Por otra parte, para elaborar una obra de arte ${ }^{6}$ la concepción budista propone realizar una larga observación del modelo, servirse de la intuición, adquirir una postura correcta y la respiración adecuada, cultivar el silencio y rechazar todo artificio. Como resultado, se consumará el tan anhelado satori (ver Sastre De La Vega).

Otro concepto de procedencia zenista, vivamente presente en el teatro Nō y en otras artes nacionales japonesas, es el $m a$, “vacío”「間 (ver Borel). ${ }^{7}$ Sin tratarse de un vacío plano y carente de sentido, el vacío zenista es vibrante y lleno de energía. En las artes tradicionales, el ma es un punto de inflexión en una obra musical o teatral, ya que subraya el equilibrio y el contraste mediante las pausas o el espacio entre los componentes de la misma.

Habitualmente, la tendencia a lo inacabado y lo asimétrico, tan propia del Zen y de las artes influidas por esta rama del budismo, entrena la imaginación del artista y del espectador, des-

6 Durante mucho tiempo, la lengua japonesa utilizaba el vocablo asobi, “juego”「遊び」, para referirse a las artes, porque el arte apenas se diferenciaba de otras manifestaciones culturales producidas por el ser humano, como la religión, la técnica, el mito, etcétera.

7 Comparar con el wu, o "no acción", del Zen chino, pero también de la milenaria doctrina taoísta. 
pertando en ambos el reconocimiento de la belleza de las cosas cuando éstas están presentes o simplemente evocadas, esbozadas, sugeridas. Así, de acuerdo con el pensamiento nipón, el ser humano está integrado en los procesos naturales, sin que tenga sentido la pretensión de dominarlos. Convivir con la naturaleza de una forma espiritual define la estética clásica japonesa, que sigue estando vigente en varios campos artísticos en la actual sociedad nipona.

\section{Algunas obras de teatro Nō de temática shintō}

Siendo coherentes con todo lo expuesto anteriormente, es de rigor comenzar nuestra pequeña nómina de piezas en las que late la esencia del shintoísmo con la antigua Danza del Okina (o Danza del anciano), cuyo origen se pierde en la noche de los tiempos. Dicha danza está aderezada con rituales propiciatorios y de purificación (ver Săpunaru Tamaş), ${ }^{8}$ lo mismo que con aquellos que desean la bonanza de los campos de labranza o de las poblaciones, algo fundamental para los antiguos japoneses (ver Heine). Por tanto, ante nuestros ojos tenemos una pieza que es teatro y, a la vez, es liturgia; que navega entre las aguas de la puesta en escena y las del ritual por el que los hombres entran en íntimo contacto con el mundo de las divinidades (kami) niponas. Desde el punto de vista escénico, esta danza no se puede incluir en ninguna de las cinco categorías en las que, tradicionalmente, se sistematizan las obras de Nō. Éstas son: obras en las que sus protagonistas son los propios kami, que tienen como interlocutores a sacerdotes shintoístas; obras dedicadas a los grandes guerreros (bushi) de la antigüedad, por ejemplo, los que campean por el imponente poema épico Heike Monogatari; las kazura-noh (literalmente, "obras Nō de pelucas"), en donde las protagonistas son mujeres desdichadas, víctimas de los celos o que han sido traicionadas por sus amantes; el cuarto grupo sería para las obras de temática miscelánea, mientras que en el último, el de las kiri-nō o piezas de demonios -que se representaban al final del programa-, los protagonistas son algún monstruo o animal fantástico. Poseen un ritmo más rápido, la intervención de la música es más notoria y terminan con una más que concluyente danza final.

También es notorio señalar que no hay en la Danza del Okina una trama argumental propiamente dicha, siendo una superposición de fórmulas propiciatorias y ensalmos. Sin embargo, en uno de los textos teóricos fundamentales de este arte, el Füshikaden, obra del aludido Zeami Motokiyo, ya se habla con hondo respeto de la ejecución de dicha pieza.

8 Días antes de comenzar la representación, el actor que encarnará a Okina deberá realizar el antiquísimo y respetado ritual del bekka, propio también de varias festividades religiosas, en el que el fuego, hecho con un pedernal, sirve como elemento purificador, tanto del alma como del cuerpo. 
En cuanto al actor que ejecuta la obra, éste debe realizar primero, antes de hacer su entrada en el escenario, varios rituales mediante los cuales purifica su cuerpo y su alma. Esta práctica señala nuevamente las influencias de la vieja religión japonesa del shintō en el ámbito teatral. Es frecuente que en las representaciones de la Danza del Okina se emplee sobre las tablas y como marco que señala aún más lo sacro que acaece ante nuestros ojos, la shimenawa, o cuerda trenzada con pajas de arroz, que también podemos encontrar enmarcando el espacio sagrado de los templos shintoístas, piedras o árboles sagrados de todo el país. Así, la Danza del Okina no es una mera actuación cuya finalidad es entretener al público, sino que los elementos religiosos -incluso nos atreveríamos a decir chamánicos, los más antiguos de Japón- también se manifiestan en cada una de sus escenificaciones. Esta danza se vive como una fiesta que se suele reservar para las fechas claves en el calendario, tales como el inicio del año, con el fin de traer buena suerte y prosperidad en la inauguración del almanaque.

Kayoko Takagi ha publicado en castellano su traducción, prologada y anotada, de la Danza del Okina, con la que el lector puede llegar a comprender el carácter híbrido, entre el ensalmo y el texto dramático, de dicha pieza. En la introducción a este texto la Takagi nos dice:

[...] existe [en la Danza del Okina] un misticismo positivo que envuelve a todo el teatro incluyendo a los espectadores. Existe una reverencia ancestral hacia la representación de esta pieza en todos los teatros del Noh. Es por ello por lo que me parece importante hablar de esta pieza bien desconocida, incluso entre los aficionados del teatro Noh en el extranjero ("Entre la liturgia y el arte" 67).

Esta observación acerca la realidad simbólico-dramática de la Danza del Okina al espectador y al lector, ya que la pieza posee la cualidad de convertirlos no ya en fieles sino en concelebrantes, mediante esa magia inexpresable que es la "simbiosis espiritual" que consigue su representación. Resaltando el carácter místico de esta obra, nos permitimos trasladar aquí su inicio, siempre en la versión de la profesora Takagi, en donde las palabras que tanto significado místico tenían para los antiguos japoneses (ver Villani), se vuelven casi una admonición de corte ritual. Comienza interviniendo el propio Okina y es el coro (jiutai) quien le responde:

Okina (cantando): Tōdōtarari tararira, tarari agarirararidō.

Jiutai: Chiriyatarari tararira, tarari agarirararidō ("Entre la liturgia y el arte" 70).

Tal y como afirma su traductora en la introducción al texto, estas palabras estarían vacías de significado y más bien querrían asimilarse al sonido del agua al caer desde una cascada, o al de la música de los instrumentos que acompañan la ejecución de toda la obra. 
Posterior en el tiempo, pero indudablemente impregnada por la esencia del shintō, es otra obra frecuente en el repertorio de las compañías profesionales de teatro Nō. Nos referimos a Takasago, que toma su nombre de una hermosa playa situada en la provincia de Harima, en el sur del País del Sol Naciente. La obra fue escrita por el gran Zeami, aunque con toda seguridad bebió de fuentes anteriores, por ejemplo, la gran antología Kokinshū, terminada de compilar hacia el 920 de nuestra era.

En Takasago, el deuteragonista (o Waki, empleando la terminología propia del Nō) es el sacerdote shintoísta Tomonari, llegado allí desde su templo de Aso ${ }^{9}$ en larga peregrinación. Este motivo, el de la peregrinación, es también frecuente en el repertorio de este género escénico. Resulta ser casi una excusa para que los hechos mágicos sucedan a personalidades religiosas que parten desde un lugar señalado para la fe del shintō o del budismo, y que llegan a sendos lugares representativos para las aludidas religiones. Por lo tanto, estos lugares, templos, bosques sagrados, etcétera, que sirven de marco para las obras, son también importantes lugares de culto para el público que asiste a la representación.

Siguiendo con la trama de Takasago, mientras Tomonari está esperando a un vecino de la población, aparece una misteriosa pareja de ancianos. A través de sus palabras elegantes, casi un discurso o un sermón religioso, sabemos que los ancianos son en realidad los kami de esos lugares, identificados por dos pinos que crecen allí, señalándose aún más la identidad mágica de dicho árbol (ver Primack y Okubo). Son dos divinidades, masculina y femenina, que se complementan entre sí. Como ocurre en la Danza del Okina, también Takasago participa de las celebraciones cotidianas de los japoneses. Aún en nuestros días, uno de sus parlamentos se sigue empleando en los enlaces matrimoniales, como signo de fidelidad absoluta entre los contrayentes. Así, el dios anciano (Shite, protagonista de la obra), es el pino de Takasago, mientras que la viejecita (Tsure, acompañante o personaje complementario del Shite), es el de la cercana playa de Suminoe; mas a pesar de la distancia que los separa, ellos se sienten siempre unidos y en armonía. Transcribimos ahora el final de la obra, en el que habla el coro y en donde, una vez más, la expresión teatral se mezcla con el ritual propiciatorio, en este caso haciendo mención a la bonanza y a una especie de conjuro para alejar a los demonios: ${ }^{10}$

$9 \quad$ Uno de los más antiguos y reverenciados de todo Japón. Su imponente arquitectura aún sobrecoge al visitante. Aso-no-Ōkami, la deidad residente de este templo, es el protector de los navegantes y también quien asegura un buen viaje, aunque éste no se haga por mar.

10 En concreto, encontramos parecido con la fórmula propiciatoria que se pronuncia en la celebración del Mamemaki, llevada a cabo el día antes del comienzo de una nueva estación del año por el cabeza de familia, en donde se grita: Oniwa soto! Fukuwauchi! (“¡Fuera los demonios, dentro la buena suerte!”). 
CORO:

Con la mano hacia afuera espantamos a los demonios, con la mano hacia adentro felicidad y prosperidad atraemos.

Con la música de mil otoños

deseamos la seguridad del pueblo.

Con la danza de los diez mil años

oramos por la larga vida del emperador.

El viento mece los pinos de Aioi.

Gozosa se oye su noble voz,

gozosa se oye su noble voz (Takagi, 9 piezas de teatro Nô 66).

La presencia del shintō aparece algo más difuminada en la pieza Yōrō, ya que se mezcla con la del budismo, también debida al prolífico Zeami Motokiyo, en donde la divinidad protectora de una montaña aparece como uno de los personajes. En esta obra queda reflejado el valor que los japoneses otorgan a las aguas, en este caso las de un manantial mágico cuya corriente otorga fuerza y juventud a quien bebe de ella. Aun hoy, viajando por el Japón más rural, es posible encontrar fuentecillas o cascadas a las que los lugareños les atribuyen estas propiedades, y ya el naturalista y médico alemán Engelbert Kaempfer (1651-1716) hizo alusión a esto en sus escritos, diciendo que algunas corrientes acuíferas japonesas atraviesan minas de sal, cobre o salitre, lo que les confería estas propiedades curativas.

Una de las obras del Nō que están más relacionadas con la tradición chamánica del shintō primigenio que con el teatro, es Aoi no Ue. En esta obra, presente en el repertorio de todas las compañías profesionales de Japón, se escenifican elementos iniciáticos, trasladándose sobre las tablas la capacidad para exorcizar de las antiguas chamanas, y cómo la mujer ostenta los poderes mágicos y es capaz de comunicarse con el más allá. Es de destacar que Aoi no Ue ha suscitado el interés de varias investigadoras en España, quienes incluso han realizado su traducción anotada (como ha sido el caso de la citada Kayoko Takagi, junto a Clará Janés), además de haberse estudiado pormenorizadamente, tal y como ha hecho Mariló Rodríguez del Alisal. Es más, en su propio país de origen, y de manos de uno de los escritores más reconocidos de todos los tiempos -Yukio Mishima (1925-1970)-, se realizó una actualización de su texto, dentro de ese experimento en el que este autor quería unir lo antiguo y lo moderno, el cual dio lugar a las piezas de Nō moderno. Fueron un total de seis piezas, ${ }^{11}$ acaso las más representativas del repertorio clásico de este arte, redactadas entre 1950 y 1955 (compiladas en el libro Seis piezas Nô de Mishima).

11 Sotoba Komachi, Aya no Tsuzumi, Kantan, Aoi no Ue, Hanjo y Dōjōji. 
Centrándonos ahora en el argumento de Aoi no Ue, una de sus protagonistas es la cortesana Aoi, que aparece en la magna novela Genji Monogatari escrita por la dama Murasaki Shikibu (c. 973 - c. 1014 d.C.), cuyos capítulos son un compendio de absolutamente todo lo tocante a la vida en el interior de los palacios del periodo Heian (794-1185). Una vez más, una mujer sufre aquí por culpa de otra mujer y por un hombre que no la respeta. Así, la joven Aoi-no-Ue vive en sus carnes los influjos malignos de la dama Rokujō, quien la atormenta mediante hechizos. Será necesaria la visita de una médium (de nuevo el sexo femenino como bisagra entre el mundo de los dioses y el de los mortales) para poner fin al dolor, y el camino elegido será el del exorcismo, que será llevado a cabo por un yamabushi ("los que se ocultan en las montañas"). Los yamabushi son unos monjes budistas anacoretas que siguen una creencia religiosa híbrida, el shugendō, en la que se mezclan, además de algunas de las enseñanzas de Buda, preceptos del shintō y también del taoísmo, en concreto, los de su vertiente más mística (ver Earhart). Tienen fama de ser hábiles curanderos y conocer las propiedades de muchas plantas y frutos; suelen vestir de blanco, el color de los dioses. En palabras de Rodríguez del Alisal:

Los ascetas itinerantes, conocidos como yamabushi, solían invocar en sus prácticas la ayuda sobrenatural de los Myō, deidades del budismo esotérico, quienes tienen capacidades de contrarrestar los maleficios y las maldiciones (tatari). En la obra Aoi no Ue, el yamabushi conocido como "el santón de Yokawa" (Yokawa Kohijiri), invoca en su ritual a los $M y \bar{o}$ de las cuatro direcciones y del centro, conocidos como los Goday Myō, mensajeros de los Cinco Budas (Go Butsu) (31).

Aoi no ue es un texto dramático en el que se dan cita elementos del pensamiento chamánico anterior al shintō, el propio shintō, el budismo en su vertiente esotérica y las creencias místicas del taoísmo, presentados en una ecuación que da como resultado el sentimiento mixto de la religiosidad de Japón que hoy en día es posible percibir en sus habitantes.

Ligada a Aoi no Ue está una obra en la que los viejos rituales nigrománticos están presentes: Kanawa, una pieza Nō de autor desconocido que es teatro y, a la par, ritual puro, donde el misticismo mágico impregna cada palabra de su texto y lo esotérico se mezcla con el horror.

En Kanawa encontraremos algo en lo que muchos japoneses de hoy en día también creen: las revelaciones hechas en los sueños, la premonición de lo que va a suceder mediante lo onírico. Aquí, quien lo vivirá será un sacerdote shintō de bajo rango, el cual recibe el mensaje de que tendrá noticias de una mujer en Kioto. La trama de Kanawa, pausada y bien medida, sería el guion inmejorable para una película de terror japonés. La historia relata cómo una noche, a las dos de la madrugada, una misteriosa dama aparece en el 
templo, donde le espera el sacerdote. Allí comienza su patético discurso, diciendo al religioso que su corazón está lleno de pena porque su marido le traicionó con otra mujer. El sacerdote empleará un oráculo, tal vez una de las creencias mágicas más respetadas por los japoneses de antaño, para decirle que si pone en su cabeza una corona con tres candelas encendidas en su parte superior (artefacto que da nombre a la pieza) y viste un kimono rojo, se convertirá en un demonio, como desea, para mortificar con su horrible presencia a la nueva esposa de su ex-marido. Este pasaje más pareciera sacado de las memorias de los antiguos hechiceros que de la pluma de un dramaturgo, por la precisión de los detalles y las palabras que va pronunciando el actor, que suenan rotundas en la sala, salmodiadas, más que recitadas. Y es que estas palabras no son humanas, sino que han sido transmitidas -se cree- por los espíritus. Así, lo que se retrata en la obra es la plasmación de lo que se ha hecho en Japón desde tiempo inmemorial: acudir a las médiums para preguntar por un problema que atormenta al fiel, para que ellas contacten con el más allá y así recibir una solución. Por otro lado, la joven esposa, víctima ya de las influencias malignas de la mujer despechada, tiene pesadillas todas las noches, lo que aún se ve en Japón como un signo de mal agüero.

No queremos develar al lector su interesante final, plagado de concomitancias religiosas y de ecos de antiguos cultos, sepultados ya hoy por el paso de los años y la sistematización del shintō; pero sin duda las invocaciones para calmar a los espíritus están presentes, lo mismo que las llamadas a los dioses y a los budas, ejemplificando, una vez más, ese sincretismo religioso del que Japón hace gala.

Cerramos este apartado refiriéndonos brevemente a otra obra antigua, casi asimilable a los misterios del teatro europeo del Medievo, que ha tenido un eco contemporáneo en formas tan populares como son el manga y el anime; ${ }^{12}$ nos estamos refiriendo a la pieza Hagoromo (El manto de plumas). Zeami dotó a la vieja leyenda de un lenguaje poético muy refinado, haciéndola casi un cuento de hadas. Aquí, una tennin (un espíritu celestial muy hermoso) baja a la tierra y se pone a danzar junto a un río, mientras un pescador contempla furtivamente su baile y cae rendido ante su belleza. Éste consigue robarle su manto mágico de plumas, sin el cual la tennin no puede volver a los cielos. El pescador le dice que se lo devolverá si le enseña su misteriosa danza, a lo que ella accede. Al margen de la trama, se vuelven a escuchar las bendiciones y las palabras propiciatorias para que llegue la paz y la bonanza al auditorio. Mientras la danza transcurre, se descubre que ésta tiene que ver con los ciclos de la luna, periodos de tiempo que también tienen un peso específico en abundantes ceremonias shintoístas, budistas

12 Por ejemplo, en un episodio de la saga del Fénix, de Osamu Tezuka, y en la serie de animación Naruto. 
o taoístas (ver Shimoi 81-94). Tan sólo extractamos, en traducción de Kayoko Takagi y Clara Janés, una de estas jaculatorias propiciatorias que aparecen en "Hagoromo":

La noche del día quince se convierte en la luz de la luna llena de la verdad búdica; ilumina la tierra y bendice los deseos de salvación (9 piezas de teatro Nô 40).

En resumen, en todas las obras analizadas en este breve artículo se cumple una misma premisa: las protagonistas son mujeres que sufren, que deben recurrir a los conocimientos sobrenaturales para apaciguar su alma o encontrar la calma. Del mismo modo, los personajes tocados por la divinidad o los que reciben sus dictados, o bien quienes solicitan la mediación de las fuerzas superiores, son también siempre mujeres, como si conformasen un nudo mágico que sella el mundo de los humanos y el numinoso universo de los kami y de los budas.

\section{Conclusiones}

Como se ha visto en lo expuesto a lo largo de nuestro trabajo, la presencia de las influencias religiosas sigue siendo significativa tanto en la vida cotidiana de los japoneses como en las artes escénicas tradicionales del País del Sol Naciente. Hundiendo sus raíces en tiempos inmemoriales, la religión se apodera del mágico escenario del teatro Nō y, en muchos casos, acude a los personajes femeninos, que sirven de conexión directa entre dos mundos: el de los seres humanos (espectadores sentados en el patio de butacas, en su caso) y el de los dioses, representados por los actores. El teatro se convierte, pues, en puente: nos acerca a los kami y a sus enseñanzas, y tal vez con ellas busque materializar un mundo mejor y más puro.

\section{Fuentes consultadas}

Anarina, Nina Grigoryevna. Японский mеamp Но. Наука: ГАавная РеАакция Восточной Аитературы, 1984.

Borel, Henri. Azione senza azione. Wu wei. L'arte spirituale del cambiamento senza violenza. Cesena: BIs, 2009.

Earhart, H. Byron, editor. Shugendō: Essays on the Structure of Japanese Folk Religion. Ann Arbor: The University of Michigan Press, 2001.

Ferranti de, Hugh. The Last Biwa Singer, A Blind Musician in History, Imagination and Performance. Ithaca: East Asia Program, Cornell University, 2009. 
Gadjieva, Ekaterina Alexandrovna. El país del sol naciente. Historia y cultura de Japón. Rostov-na-Donu: Fénix, 2006.

Goreglyad, Vladislav, traductor. Kojiki. Ulán Udé: Kristall, 2000.

Habu, Junko. Ancient Jömon of Japan. Cambridge: Cambridge University Press, 2004.

Heine, Steven. "From Rice Cultivation to Mind Contemplation: The Meaning of Impermanence in Japanese Religion." History of Religions, vol. 30, núm 4, 1991, pp. 373-403.

Hekmat Fereshteh, Farshad y Morteza Ghaffari. "Investigating the Impact of Zen Buddhism on Theory and Practice of Japanese Noh Theatre". Journal of Art E Civilization of the Orient, vol. 25, núm. 7, 2019, pp. 31-40.

Lanzaco Salafranca, Federico. Introducción a la cultura japonesa. Pensamiento y religión. Valladolid: Universidad de Valladolid, 2000.

Lanzaco Salafranca, Federico. Los valores estéticos en la cultura clásica japonesa. Madrid: Verbum, 2003.

Lanzaco Salafranca, Federico. Religión y espiritualidad en la sociedad japonesa contemporánea. Zaragoza: Colección Federico Torralba de Estudios de Asia Oriental, Prensas Universitarias de Zaragoza, 2008.

Mishima, Yukio. Seis piezas Nô. Traducido por Vicente Ribera Cueto \& Masae Yamamoto. Barcelona: Seix Barral, 1973.

Ohnuki-Tierney, Emiko. “The Emperor of Japan as Deity (Kami).” University of Pittsburgh of the Commonwealth System of Higher Education. Ethnology, vol. 30, núm, 1991, pp. 199-215.

Primack, Richard y Tatsuhiro Okubo. "Ancient and Notable Trees of Japan: Then and Now". Arnoldia, vol. 3, núm. 65, 2008, pp. 10-21.

Rodríguez del Alisal, Mariló. "Posesión, trance y exorcismo en el teatro Noh: Acerca de la obra Aoi no Ue”. La Ratonera. Revista Asturiana de Teatro, núm. 31, 2011, pp. 22-30.

Rodríguez-Izquierdo, Fernando. El haiku japonés. Historia y traducción. Madrid: Hiperión, 2001.

Săpunaru Tamaş, Carmen. "Salt, Fire and Water: Means of Entering the Sacred". Cogito. Multidisciplinary Research Journal, núm. 2, 2012, pp. 95-111, https://www.ceeol. $\mathrm{com} / \mathrm{search} /$ article-detail?id=94551, consultado el 5 de abril de 2021.

Sastre De La Vega, Daniel. Arte y nación. El discurso de la historia del arte en el Japón Meiji. Barcelona: Bellaterra, 2019.

Smith, Henry, editor. Learning from Shōgun. Japanese History and Western Fantasy. Santa Barbara: University of California, Program in Asian Studies, 1980.

Shimoi, Harukichi. "Feste popolari in Giappone", Buio sotto il faro (a cura di Ugo Piscopo). Nápoles: Guida Editori, 2015, pp. 81-94. 
Takagi, Kayoko. "Entre la liturgia y el arte: la pieza Okina en el teatro Noh", La Ratonera. Revista asturiana de teatro, núm. 31, 2011, pp. 67-73.

Takagi, Kayoko, y Clara Janés. 9 piezas de teatro Nô. Madrid: Ediciones del Oriente y del Mediterráneo, 2008.

Villani, Paolo. "Oralità e scrittura nel Giappone antico. Il potere delle parole in una canzone del Kojiki". Oriente, Occidente e dintorni. Scritti in onore di Adolfo Tamburello (a cura di Franco Mazzei e Patrizia Carioti). Nápoles: Università degli Studi di Napoli "L'Orientale", 2010, pp. 2509- 2513.

Yamazaki, M. editor. On the Art of the Nô Drama: The Major Treatises of Zeami, Princeton: Princeton University Press, 1984. 